\title{
Estética de la existencia y resiliencia en la vida-obra de Frida Kahlo*
}

\author{
Aesthetics of existence and resilience in Frida Kahlo's \\ life-work
}

Julián Andrés Lasprilla Burbano**

Rec: 4/04/2019

Acep: 21/07/2019

\section{Resumen}

Este artículo se deriva del trabajo de investigación vinculado al proyecto Antropología evolutiva, resiliencia y empatía. El objetivo principal es entablar un diálogo entre las nociones de estética de la existencia y de resiliencia a través de la vida-obra de la artista mexicana Frida Kahlo, en aras de comprender lo que nos enseña a través de su obra: la capacidad de metamorfosear sus sufrimientos en una obra de arte. Esto, como propuesta estética y ética frente al acontecimiento traumático.

Palabras clave: Resiliencia, Frida Kahlo, oxímoron, vida-obra, estética de la existencia, acontecimiento traumático.

\begin{abstract}
This article derives from the research project Antropología evolutiva, resiliencia y empatía. (Evolutionary anthropology, resilience and empathy) The aim is to open a dialogue between the notions of aesthetics of existence and resilience through Frida Kahlo's life-work in order to understand what she show us through her work: The capacity to metamorphose her sufferings into a work of art. This, as an aesthetical and ethical proposal facing the traumatic event.
\end{abstract}

Keywords: Resilience, Frida Kahlo, oxymoron, life-work, aesthetics of existence, traumatic event.

* Artículo de reflexión del grupo de investigación Lumen Humanitas y del proyecto de investigación Antropología evolutiva, resiliencia y empatía, Fundación Universitaria Católica Lumen Gentium, Cali, Colombia (2017-2018).

** Licenciado en Filosofía de la Universidad del Valle, Cali, Colombia. Magíster en Filosofía y Críticas Contemporáneas de la Cultura de la Universidad de Paris 8, París, Francia. Master en Psicoanálisis de la Universidad Paris de 8. Formado en la Sección Clínica de Paris-Saint-Denis. Profesor del Programa Académico de Psicología, Fundación Universitaria Católica Lumen Gentium, Cali, Colombia. Correo electrónico: julianandreslasprilla@ gmail.com. Orcid: 0000-0002-4755-7207. 


\section{Introducción}

¿Hacer de su vida una obra de arte? En 1983, Michel Foucault (1994/2001, p. 392) se encontraba hacia el final de su vida, cuando en un viaje académico a la Universidad de Berkeley, California, sus estudiantes le preguntaron sobre el tipo de moral que se podría elaborar en nuestra época. Ante este cuestionamiento, Foucault expresó que le llamaba la atención la forma en que el arte en las sociedades contemporáneas se había destinado a los objetos y no a las personas ni a la vida. ¿Por qué si la Rueda de bicicleta, de Marcel Duchamp (1913), por ejemplo, es una obra de arte, la vida de una persona no podría serlo? La respuesta de Foucault se inscribió en una apuesta por una estética de la existencia, caracterizada por la manera en que las personas pueden elegir hacer de su vida una obra de arte.

Es así como foucault sostuvo que la principal obra de un ser humano sería su vida misma, a partir de la cual es necesario preocuparse, ocuparse de sí mismo. Valorar estéticamente su propia existencia implica una respuesta ética por parte del sujeto que expresa su deseo de transformarse de acuerdo con su naturaleza o los valores éticos, formas y sensibilidades de su propia existencia. Para desarrollar dicha apuesta, Foucault retoma las enseñanzas filosóficas de los antiguos griegos y romanos (Desde el "conócete a ti mismo" de Sócrates a las escuelas estoicas y epicúreas del periodo helénico, principalmente), quienes desarrollaron una estética de la existencia basada en el cuidado de sí y las tecnologías del yo (Foucault, 1984;1990).

Por un lado, el "cuidado de si" hace referencia al trabajo ético iniciático que cada persona decide emprender gracias a un ejercicio reflexivo e indagatorio de su propia existencia que da lugar al sentimiento de preocuparse, de ocuparse e inquietarse de sí mismo; por otro lado, las "tecnologías del yo" aluden a la manera en que el sujeto construye dispositivos o artefactos simbólicos mediados por las artes de la vida, desde una estética que le permite hacerse responsable de su vida y gobernarla de manera digna. Es así como dichas tecnologías convergen al interrogar las prácticas de vida del sujeto y potenciar una manera de pensar la invención de sí mismo.

El objetivo de este artículo es mostrar la relación entre estética de la existencia y resiliencia, tomando como caso para ilustrar dicha relación la obra y la vida de la artista mexicana Frida Kahlo. Con la expresión vida-obra se pretende dar a comprender la manera en que el arte fue inseparable de las experiencias de vida de la artista. Esto busca explorar el potencial estético y ético de sus obras, y su posición subjetiva frente a los distintos traumas y experiencias dolorosas que tuvo a lo largo de su vida. El caso de Frida Kahlo permite apreciar un saber-hacer con el sufrimiento vivido por la experiencia traumática que revela su capacidad resiliente desde una fenomenología de los significados psicológicos de la artista. Para desarrollar lo anterior, se llevó a cabo un trabajo cualitativo de tipo hermenéutico e interpretativo a través de la revisión documental de algunos textos y datos biográficos de la vida de Frida Kahlo, descritos por la biógrafa Hayden Herrera en su libro Frida, una biografía de Frida Kahlo (2002), y también los aportes sobre la noción de resiliencia del neuropsiquiatra francés Boris Cyrulnik (2002; 2003).

\section{Frida Kahlo: una vida-obra de arte}

Cuando Magdalena Carmen Frida Kahlo y Calderón afirmaba que no necesitaba pies, porque en su lugar tenía alas para volar, constataba su filosofía de vida, cuya experiencia traumática vivida no la sometió al destino trágico del sufrimiento. Frida pintó su propia vida a través de lo que su cuerpo-psique vivió. El accidente del tranvía, las múltiples cirugías, las alegrías, las penas amorosas y los abortos, marcaron su vida. La artista mexicana logró plasmar en sus obras algunas de las imágenes más potentes sobre el cuerpo femenino del siglo XX. Frida se pintó a si misma hecha pedazos, 
llorando, sangrando, pero también amando y disfrutando de la vida y la naturaleza. Toda la obra de Frida es una autobiografía donde figura su propia estética de la existencia y su capacidad resiliente de retomar un desarrollo psicológico digno de su arte, a pesar de los traumas vividos.

Para comenzar a hablar de Frida, es importante hacer referencia a la Casa Azul de la calle de Londres y Allende en Coyoacán, México. Su hogar que hoy en día es conocido también como el Museo Frida Kahlo y que alberga muchos de sus cuadros y objetos personales, convertidos en íconos de la identidad de la artista. Frida nació el el 6 de julio de 1907, sin embargo, ella eligió 1910 como el año de su nacimiento, momento en que comenzó la revolución mexicana, motivo por el cual Frida afirmó que ella nació con la revolución.

El padre de Frida fue Guillermo Kahlo, fotógrafo profesional de quien Frida aprende el arte del autorretrato que se evidencia en sus pinturas. Para Frida, sus cuadros eran como las fotografías hechas por su padre y que ella atesoraba en su cabeza como recuerdos de infancia y adolescencia. Guillermo Kahlo se casó con Matilde Calderón, Frida fue la tercera hija y sin duda, la preferida de su padre. El amor y admiración la unió a su padre; sin embargo, con su madre mantuvo una relación distante, ya que la consideraba fanática religiosa y fría. Al poco tiempo de nacer Frida, su madre se enfermó y una nodriza indígena la cuidó y amamantó por un tiempo: "Me crió una nana cuyos senos se lavaban cada vez que iba a mamar, olía ella a tortillas y a jabón" (Herrera, 2002, م.27).

Tiempo después, Frida recordaría esto como algo importante. Ella fue alimentada por la leche de una indígena, lo que simbolizó para ella su conexión con las raíces y fuerza vital de su herencia mexicana. Esto se evidencia en su obra: Mi nana y yo (Kahlo, 1937), en la que está representada allí la mujer indígena que la amamantó y Frida en sus brazos con cuerpo de niña y rostro de mujer grande. La nodriza indígena, grande y morena, enigmática con su rostro cubierto por una máscara de piedra, representa la mujer protectora que la nutre con una leche que se enraíza en la tierra.

Tanto el padre de Frida como la nodriza indígena son dos tutores de resiliencia. Estos se comprenden como figuras de apego seguro con quienes Frida estableció una conexión o un lazo de empatía temprano que le permitió construir un mecanismo moderador del riesgo patógeno frente a la vulnerabilidad. Frida se identificó con ambos, interiorizando por el lado de su padre la técnica de la fotografía y el autorretrato, que luego ella utilizó como técnica del yo para plasmar en sus pinturas su realidad; y por el lado de su nodriza indígena, su conexión con la fuerza, vitalidad y enigma de la mujer y cultura ancestral mexicana. Estos tutores de resiliencia son factores protectores fundamentales en su devenir resiliente, ya que son recursos externos que fueron interiorizados por Frida. Los tutores de resiliencia se relacionan con el concepto del "otro significativo", factor de apoyo fundamental descrito por Boris Cyrulnik, en su obra Los patitos feos (2002).

Frida era una niña alegre y encantadora, pero al cumplir los seis años contrajo poliomielitis. Esta enfermedad generó un cambio en ella a nivel de su personalidad, ya que adquirió una expresión introvertida y algo sombría. Debido a esto, permaneció nueve meses en su cuarto: "Todo comenzó con un dolor terrible en la pierna derecha, desde el muslo hacia abajo", recordaba, "me lavaban la piernita en una tinita con agua de nogal y pañitos calientes" (Herrera, 2002, p. 32).

Es probable que, como consecuencia de los cuidados de esta enfermedad y sus largas horas a solas, Frida creara una amiga imaginaria, hecha a su imagen y semejanza como compañera, amiga, confidente, consoladora y cómplice de sus fantasías. 


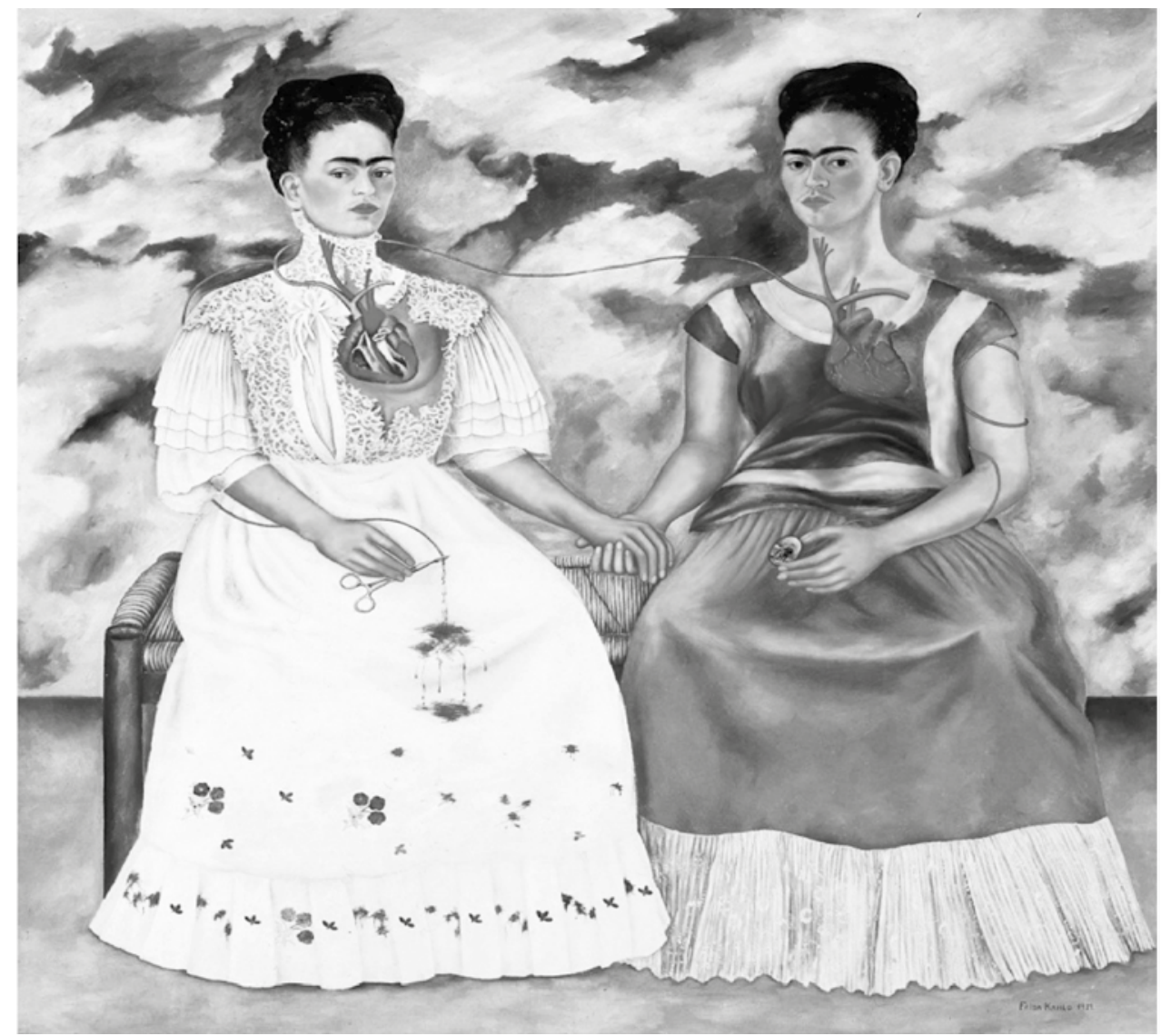

Figura 1: Representación pictórica de las dos Fridas Kahlo, F. (1939). Las dos Fridas. [Óleo sobre lienzo]. Museo de Arte Moderno de México.

Fuente: https://mam.inba.gob.mx/las-dos-fridas-historia-de-dos-ciudades

Al respecto, Frida, en su diario también relacionó este hecho con el origen de una de sus obras más conocidas Las dos Fridas (1939):

Debo haber tenido seis años cuando viví intensamente la amistad imaginaria con una niña de mi misma edad más o menos. En la vidriera del que entonces era mi cuarto y quedaba a la calle de Allende. Sobre uno de los primeros cristales de la ventana echaba vaho y con el dedo dibujaba una puerta. Por esa puerta salía en la imaginación con gran alegría y urgencia. Atravesaba todo el Llano que se miraba, hasta llegar a una lechería que se llamaba Pinzón... Por la "o" de Pinzón entraba y bajaba impetuosamente al interior de la tierra, donde mi amiga imaginaria me esperaba siempre [...] Han pasado 34 años desde que viví esa amistad mágica y cada vez que la recuerdo, se aviva y se acrecienta más y más dentro de mis mundos (citado por Herrera, 2002, p. 32)

Una amiga imaginaria es un recurso importante que da cuenta de la capacidad de ensoñación, creatividad y fantasía de Frida en un momento temprano de su vida. Si bien, una amiga imaginaria para una niña puede significar su confidente y acompañante en su desarrollo psicosexual que la prepara hacia el tránsito a la preadolescencia (Kaplan, 2000), en el caso de Frida, esta amiga imaginaria la acompañó en su soledad y silencio, cuya presencia le daba una gran felicidad y el recuerdo de su infancia que aparece con algo de nostalgia. Este es otro factor interno protector resiliente. La capacidad de ensoñación coloca, en primer plano, el mundo interno que Frida 
ha construido, lleno de elementos simbólicos e imaginarios que le permitieron crear realidades alternas a su sufrimiento infantil. La creación de esa amistad mágica es un recurso simbólico de su vida íntima que le permite representar su dolor temprano, en esta la narrativa aparece como otro mecanismo potente en el devenir resiliente y la metamorfosis de su sufrir.

Al observar la obra Las dos Fridas (1939), se puede apreciar en autorretrato la escisión imaginaria del Yo de Frida. Una Frida vestida de tehuana y otra de blanco, ambas entrelazadas por un cordón que alude a las venas rojas que las conectan en su vida y sufrimiento. Las gotas de sangre que corren sobre su vestido blanco recuerdan sus múltiples abortos. La personalidad dividida, partida en dos, es un indicio del fuero interno habitado por el dolor. Una cara muestra aquello que los demás desean ver: un rostro alegre; mientras que la otra cara enseña aquello que los otros no comprenden: su agonía.

Agonía psíquica, dolor o sufrimiento íntimo como consecuencia de dos grandes traumas o accidentes que Frida denominó a partir del encuentro amoroso con Diego Rivera y el accidente del tranvía. Fue así como Frida confesó haber tenido dos accidentes graves: el del autobús y Diego.

\section{Dos grandes traumas}

Según Sigmund Freud (1920), el trauma psíquico hace referencia a uno de los posibles encuentros de una persona con lo real de la muerte. Este puede ser por accidente mecánico o choque emocional, los cuales pueden devastar al sujeto. El trauma psíquico se caracteriza por la fractura ocasionada por el acontecimiento traumático y su posterior retroactividad. La eficiencia del traumatismo psíquico se adquiere siempre a-posterioriy en aprèscoup. Esto quiere decir que la resiliencia vendría a interrogar la temporalidad del traumatismo. Esto es fundamental para comprender el hecho de que una persona puede ser resiliente cuando confronta ulteriormente la manera en que ha significado el traumatismo. Hay personas que pueden ser resilientes para cierto trauma y no para otros. Lo cual desmitifica la resiliencia como un antídoto universal contra el dolor. En el caso de Frida Kahlo, el encuentro con el amor supuso un encuentro con lo real traumático: una maravillosa desgracia. Expresión de Cyrulnik que hace referencia al oxímoron en tanto figura retórica que incluye la contradicción o ambivalencia de una situación. Veamos a continuación lo ocurrido con Frida y el amor.

\section{El amor}

Frida experimentaría el amor y la sexualidad tanto con hombres como mujeres. No obstante, Frida, desde que era adolescente se enamoró de Diego Rivera, célebre muralista mexicano. Cierto día, mientras que Frida estaba con sus amigas comiendo helado, pasó Diego Rivera. Al verlo, Frida dijo lo siguiente:

Mi ambición es tener un hijo con Diego Rivera, algún día se lo voy a decir. Sus amigas dijeron que por más de que Diego Rivera fuera el mejor muralista de México, era un viejo barrigón, mugriento, de aspecto horrible con cara de sapo; ante esto, Frida replicó diciendo: Diego es bondadoso, cariñoso, sabio, y encantador, yo lo lavaría y lo limpiaría". Frida misma recordaba que, aunque se burlaba de Diego con apodos como "viejo panzón”, siempre pensó, al mismo tiempo: "ya verás, panzón; ahora no me haces caso, pero algún día tendré tu hijo". (Herrera, 2002, p. 53)

En el pasaje anterior se puede apreciar la manera en que Frida prontamente vio a Diego Rivera en su vida con ilusión y amor idílico, propio de una adolescente. No obstante, su vida amorosa comenzó con Alejandro a la edad de 16 años. En principio fue su compañero del colegio, luego su cuate y finalmente su novio. En 1928 Frida terminó su relación con Alejandro, sufre por ello, pero poco tiempo después 
se enamoró de Diego, tras haberse integrado al Partido Comunista Mexicano por voluntad propia e identificación con su pueblo.

Para Frida, Diego era su hijo grande, un hombre grande y gordo que fue acogido por un amor maternal y pasional a la vez. Tiempo después, en 1929, Frida Kahlo se convirtió en la tercera esposa de Diego Rivera, un hombre que abiertamente fue diagnosticado por su médico como incapaz para la monogamia. Frida sufrió mucho al lado de Diego por las decepciones amorosas. A pesar de esto, ella no se victimizó y disfrutó de varios amantes entre ellos: León Trosky, André Bretón, Jacqueline Lamba, Nickolas Muray y Chavela Vargas.

\section{El accidente del tranvía}

El 17 de septiembre de 1925, tuvo lugar el accidente que marcaría la vida de Frida Kahlo. Fue un encuentro con lo real de la muerte, un horror que se instalaría en su cuerpo hasta el final de su vida. Frida y Alejandro iban en un autobús con destino a Coyoacán, el vehículo perdió los frenos y se estrelló con un tranvía procedente de Kochimilco. Frida lo recordó así:

A poco de subir al camión empezó el choque. Antes habíamos tomado otro camión; pero a mí se me perdió una sombrillita y nos bajamos a buscarla; fue así que subimos a aquel camión que me destrozó [...] en mi no hubo lágrimas, el choque nos botó hacia delante y a mí el pasamanos me atravesó como la espada a un toro, también perdí mi virginidad. (Herrera, 2002, p. 72)

Este evento traumático marcó la vida de Frida en un antes y un después. En su diario íntimo, Frida confesó nunca haber podido representar en sus pinturas el momento del accidente. El choque intenso la confrontó con la muerte y la pérdida de su virginidad. Muerte y sexualidad se entrelazaron en este accidente, en el que la barra de hierro del pasamanos del autobús atravesó a Frida de lado a lado a la altura de la pelvis. Durante un mes Frida estuvo hospitalizada, luchando entre la vida y la muerte. Su columna vertebral astillada en tres partes; su pierna derecha sufrió once fracturas y el pie derecho fue dañado. La pelvis fracturada en tres partes. Lo más impactante fue la manera en que el pasamanos de acero la atravesó por el lado izquierdo del abdomen y salió por la vagina. Ante esto, Frida afirmó: "No hay remedio, debo soportarlo [...] estoy empezando a acostumbrarme al sufrimiento" (Herrera, 2002, p. 75).

A partir de este momento, el dolor y el coraje se convirtieron en dos estados afectivos recurrentes a lo largo de la vida de Frida. Después del acontecimiento traumático, el mundo de Frida quedó despojado de sentido. Su cuerpo, hecho pedazos, fragmentado y a la deriva del sufrimiento, no fue un impedimento para que Frida abriera sus alas, volara y comenzara a pintar.

La pintura es un recurso externo que se constituye como un factor protector resiliente, ya que es una herramienta que le permitió a Frida proyectar, exteriorizar sus estados de ánimo y afectos para plasmarlos en sus obras. El trabajo de creación se pondrá en marcha, dando lugar a la operación salvífica de la metamorfosis del dolor. La resiliencia siempre en après-coup, después del choque traumático, puesta a prueba por la estética de la existencia como elección subjetiva.

Un año después del accidente, Frida escribe a Alejandro las siguientes líneas conmovedoras ilustrando el instante traumático:

¿Por qué estudias tanto? ¿Qué secreto buscas? La vida pronto te lo revelará. Yo ya lo sé todo, sin leer ni escribir. Hace poco, tal vez unos cuantos días era una niña que andaba en un mundo de colores, de formas precisas y tangibles. Todo era misterioso y algo se ocultaba; la 
adivinación de su naturaleza constituía un juego para mí. ¡Si supieras lo terrible que es alcanzar el conocimiento de repente, como si un rayo dilucidara la Tierra! Ahora habito un planeta doloroso, transparente como el hielo. Es como si hubiera aprendido todo al mismo tiempo, en cosa de segundos. Mis amigas y mis compañeras se convirtieron lentamente en mujeres. Yo envejecí en algunos instantes, y ahora todo es insípido y raso. Sé que no hay nada detrás, si lo hubiera lo vería... (Herrera, 2002, p. 75)

Como si hubiese sido atravesada por un rayo, Frida logró súbitamente el conocimiento suficiente para vivir: confrontó la muerte en carne propia. Este hecho la "envejeció" en unos instantes. Es aquí donde la herida profunda y la vulnerabilidad de Frida le permitieron abrir un camino hacia la elección ética por la vida y su reafirmación: su capacidad resiliente puesta a prueba por la estética de su existencia. Aquí es donde la dimensión del traumatismo y la resiliencia se confrontan en el después del golpe del trauma. Así, la definición de resiliencia propuesta por Boris Cyrulnik que condensa las ideas que se han descrito anteriormente:

Designa la capacidad humana de superar traumas y heridas [...] No es una receta de felicidad, sino una actitud vital positiva que estimula a reparar daños sufridos, convirtiéndolos, a veces, hasta en obras de arte. Pero la resiliencia difícilmente puede brotar en la soledad. La confianza y solidaridad de otros, ya sean amigos, maestros o tutores, es una de las condiciones para que cualquier ser humano pueda recuperar la confianza en sí mismo y su capacidad de afecto. (Cyrulnik, 2003, p. 2)

De acuerdo con el párrafo anterior, la resiliencia es una capacidad humana que involucra una actitud emancipadora frente a la vida. A continuación, se presenta la manera en que Frida convirtió sus sufrimientos en obras de arte.

\section{Resiliencia y estética de la existencia}

Después del accidente Frida Kahlo fue intervenida por médicos y cirujanos quienes le practicaron treinta y dos operaciones quirúrgicas en veintinueve años, la mayoría en la columna y el pie derecho y que concluyen con la amputación de su pierna derecha en 1953. Frida usó en sus últimos diez años de vida veintiocho corsés: uno de acero, tres de cuero y los demás de yeso, y permanecía largo tiempo estirada en posición casi vertical con bolsas de arena amarradas a sus pies para enderezar la posición de la columna vertebral (Herrera, 2002). Además, Frida tuvo al menos tres abortos terapéuticos y cuatro espontáneos, lo que le provocaba adicionalmente a su dolor físico, gran sufrimiento emocional. Es así, en esta situación, que Frida, sometida a la inmovilidad para combatir su dolor, empezó a pintar.

La obra de Frida Kahlo, a pesar de ser definida por ella misma como parte de su realidad, fue identificada por muchos como una producción surrealista debido a las escenas que representaba con aires de ficción o de excesiva realidad. Lo cierto es que la obra de Frida no tiene una definición o categoría, sino que se abre a la pluralidad de interpretaciones por parte del espectador. Esto debido a que Frida a través de su trabajo constantemente se caracterizó por la dualidad y la ambivalencia de sus temas: se lanzaba de la esperanza a la desesperanza, de la alegría al dolor, de la noche al día, de la realidad a la fantasía, de la muerte a la vida y visceversa. Es aquí que el oxímoron adquiere su importancia para contrarrestar en términos estéticos el dolor alienante.

Su cuerpo roto, despedazado evoca la violencia aterradora del trauma. La fragmentación del cuerpo exalta una profunda soledad y crisis de la unidad apaciguadora del cuerpo. Frente a esto, los fragmentos dispersos no están petrificados. Estos se articulan con otros fragmentos que revelan su dinamismo, el poder del trabajo de Kahlo adviene a 
través de su capacidad resiliente. Frida sublima su condición miserable, elevando su cuerpo a la dignidad de su arte. Así, Frida continuó pintando sus autorretratos, mirándose en el espejo. De hecho, logró pintarse mientras estaba colgada de un dispositivo para estirar su columna.

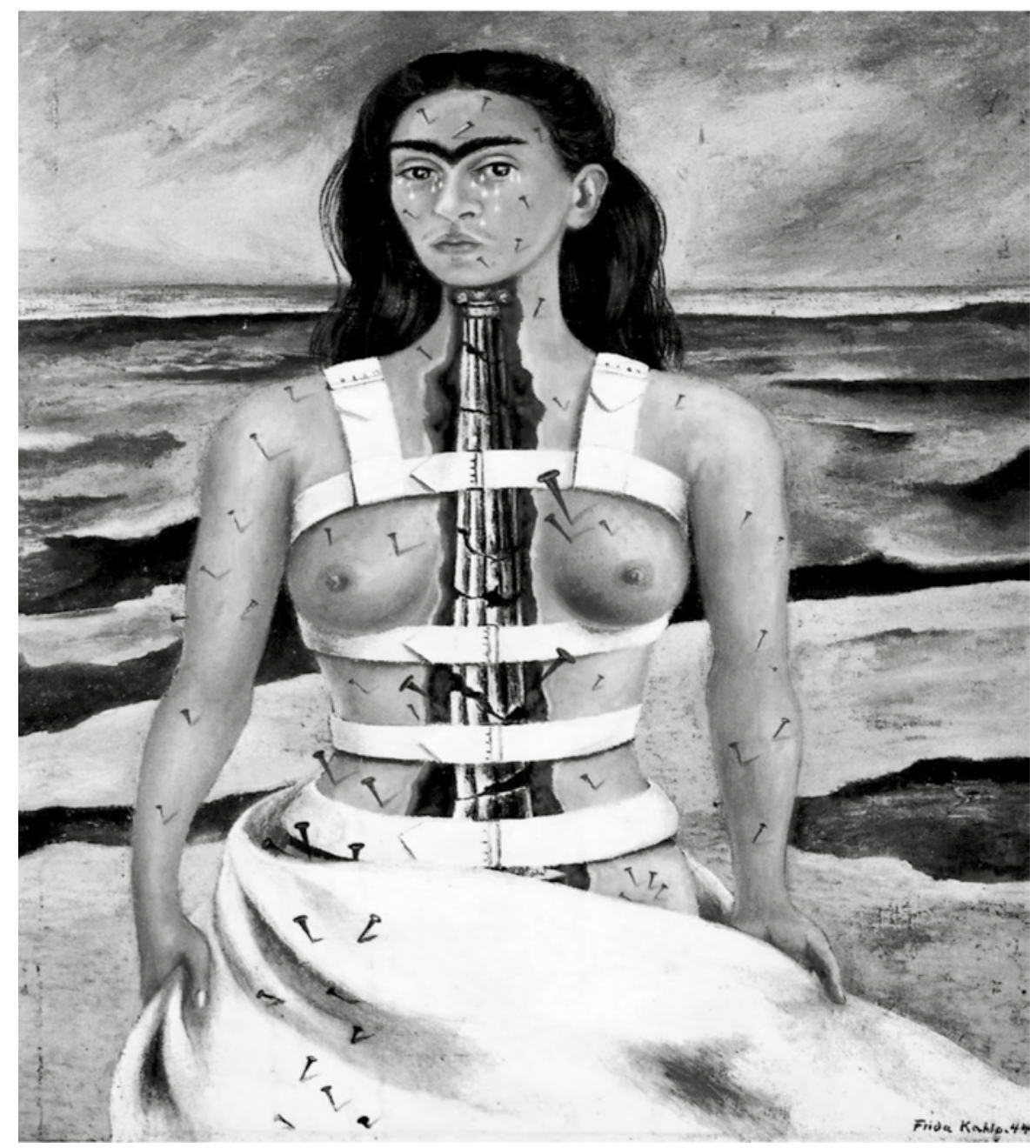

Figura 2: Representación pictórica de la columna rota de Frida Kahlo Kahlo, F. (1944). La columna rota. [Óleo sobre lienzo].Museo Dolores Olmedo.

Fuente: https://historia-arte.com/obras/la-columna-rota

Una de sus obras más representativas es La columna rota (1944), en ella Frida representa su cuerpo a través de una columna jónica rota en algunos niveles. Se aprecia también que contiene su cuerpo gracias a un corsé que revela la desnudez de sus senos. El cuerpo herido y la soledad radical se encuentran en un desierto agujereado. Se puede sentir el sufrimiento que vive Frida al identificar unos clavos que lastiman su cuerpo. Al respecto, Frida escribió en su diario: "La esperanza, conteniendo la angustia; la columna rota y la visión inmensa, sin caminar, por el camino extendido] moviendo mi vida, hecha de acero". (Herrera, 2002, p. 73).

A través de sus obras Frida Kahlo habló del dolor, de la soledad, de las mujeres, de México y sus tradiciones. Frida Kahlo era coqueta y seductora, amaba la vida, los animales exóticos, los perros y los monos. Tenía un sentido del humor muy agudo. Aquí es necesario resaltar el humor como un 
factor protector interno resiliente. Poder reírse de su propia tragedia es el mejor antídoto que existe para alivianar la pesadez existencial. Además, en sus pinturas también se aprecia la manera en que la escritura traumática en el cuerpo de Frida fue transformada a su multiplicidad identitaria: Frida la Tehuana, la colegiala, la revolucionaria, la amorosa, la herida, la esposa, la amante, la comunista, la diosa, la lesbiana, Frida y su realidad múltiple, en su inmensa pluralidad fragmentaria y unificada, por lo que su nombre y sus obras han llegado a simbolizar para los demás.

De este modo, por la vía de la sublimación, Frida da cuenta de una elección subjetiva y ética: ¿Cómo vivir con esta fragmentación traumática en su cuerpo y qué hacer con ella? La respuesta se orienta hacia la ética de su deseo. Un deseo que está del lado de la vida y la dignidad de hacer algo con su sufrimiento. Su obra es un tratamiento de lo real traumático de su cuerpo y de su psique. Sus pinturas le permitieron reagrupar su desintegración corporal y psicológica.

\section{A modo de conclusión}

En la segunda parte de La maravilla del dolor (2001), titulada "Soles negros sin melancolía", cyrulnik resalta el poder transmutador del oxímoron, afirmando que todas las penas son soportables si las convertimos en relato. Frente al horror del trauma vivido, Frida decidió adoptar una postura ética frente a sí misma al contar a través de sus obras de arte su dolor. Interpretar el pasado a la luz del presente para darle un nuevo sentido a los acontecimientos traumáticos es una operación fundamental en el proceso resiliente.

Aquí se aprecia la manera en que Frida, a través de la estética de la existencia difuminó su realidad traumática, lo cual le permitió narrar tejidos afectivos que también, a través de nuevas imágenes, le permitieron habitar el mundo del otro desde otra posición. De esta manera, la resiliencia y la estética de la existencia son una elección del sujeto que le permite pensar y sentir a la vez una filosofía de vida que va de la desgracia a la gracia y dignidad humana. Una decisión ética.

En cuanto a la estética de la existencia propuesta como elección ética y de libertad, se analiza la forma en que Frida potencia dicha elección subjetiva como una respuesta ante el cuestionamiento de cómo un sujeto después de un trauma puede constituirse de manera ética. El cuidado de sí y las técnicas del Yo animan al conocimiento de sí mismo asociado a la dimensión ética del gobierno de sí que nos abre el camino hacia una vida política entre seres humanos estéticos.

Para finalizar, se comprende la manera en que Frida Kahlo a través de su obra fue más allá del dolor carnal. No se sometió a la ley universal de una mujer humillada y desgarrada, sino que creó su propia ley vinculada a su deseo de vivir. Un ser y estar resiliente vinculados a su elección estética que le permitió revelarse frente al destino trágico del trauma. La artista mexicana fue más allá de su accidente que la dejó parapléjica de por vida. Su cuerpo despedazado se convirtió en un acto poético. Frida vivió la inefable gracia de la recompensa por la obra de arte. Esto es obra del proceso de metamorfosis del dolor que potenció a través de sus pinturas tener un recuerdo universal glorioso de Frida Kahlo. ¿Qué extraña necesidad de narrar su vida y qué extraño placer también? La vida de Kahlo se refleja en su trabajo artístico: una vida-obra de arte elevada gracias a su capacidad resiliente.

\section{Bibliografía}

Cyrulnik, B. (2001). La maravilla del dolor. El sentido de la resiliencia. Barcelona: Ed. Granica. 
Cyrulnik, B. (2002). Los patitos feos. La resiliencia: una infancia infeliz no determina la vida. Madrid: Ed. Gedisa.

Foucault, M. (1984) Historia de la sexualidad III. La inquietud de si. Madrid: Siglo XXI.

Foucault, M. (1990). Tecnologías del yo, Barcelona, Paidós.

Foucault, M. (1994/2001). Quarto Gallimard. A propos de la généalogie de l'éthique: aperçu du travail en cours, Dits et écrits, $n^{\circ} 326$ ( $\rho \rho .1428-$ 1450). (Traducción personal).

Freud, S. (1920). Más allá del principio de placer. In, AE, vol. XVIII. (pp. 1-62). Buenos Aires: Amorrortu.
Herrera, H. (2002). Frida, una biografía de Frida Kahlo. México: Ed. Diana.

Kahlo, F. (1939). Las dos Fridas. [Óleo sobre lien20]. Museo de Arte Moderno de México. Fuente: $\quad$ https://mam.inba.gob.mx/ las-dos-fridas-historia-de-dos-ciudades

Kahlo, F. (1937). Minana y yo. [Óleo sobre lienzo]. Museo Dolores Olmedo. http://www.fundacionindex. com/gomeres/?attachment_id=1562

Kahlo, F. (1944). La columna rota. [Óleo sobre lienzo]. Museo Dolores Olmedo. https://historia-arte. com/obras/la-columna-rota

Kaplan, L. (2000). Adiós a la infancia. Barcelona: Paidós. 